\title{
Success of small-dose fractionated sodium thiosulfate in the treatment of calciphylaxis in a peritoneal dialysis patient
}

\author{
Yuan Lu, Lei Shen", Ling Zhou and Deyu Xu
}

\begin{abstract}
Background: Calciphylaxis, or calcific uremic arteriolopathy (CUA), is a rare, fatal disorder of microvascular calcification and thrombosis that typically affects patients with end-stage renal disease (ESRD) receiving long-term dialysis. Fewer reports describe calciphylaxis in peritoneal dialysis patients than hemodialysis patients as per a literature review. To date, there are no clear guidelines for CUA diagnosis and treatment. While sodium thiosulfate (STS) has been increasingly used for treatment in recent years, there have also been reports of severe side effects. There is no uniform standard for its usage and dosage, especially for peritoneal dialysis patients.

Case presentation: We present a case of a 40-year-old Chinese male patient with ESRD on peritoneal dialysis who developed calciphylaxis with severe painful cutaneous ulcers on the fingers and toes that were managed successfully for 6 months with comprehensive treatment composed mainly of small-dose fractionated sodium thiosulfate.
\end{abstract}

Conclusions: Our experience suggests that the treatment of calciphylaxis requires timely and multi-angle intervention. Treatment with small-dose fractionated sodium thiosulfate has proven effective and tolerated in this patient.

Keywords: Calciphylaxis, Sodium thiosulfate, Peritoneal dialysis, Vascular calcification

\section{Background}

Calciphylaxis is a severe vascular disease mainly characterized by systemic small artery calcification combined with endothelial destruction and thrombosis that can affect the skin and other organs. The injured skin site is usually accompanied by stubborn pain, which can progress to ulcers and ischemic necrosis of the surrounding tissues [1]. The pathogenesis of calciphylaxis is not yet clear, and there is no approved therapy for it. The mortality rate is high due to sepsis and internal organ failure [2], so active treatment should be initiated once diagnosed. A multidisciplinary and multifaceted approach is considered crucial in the treatment of calciphylaxis. Retrospective data reveal that sodium thiosulfate is promising

*Correspondence: shenlei2073@163.com

Department of Nephrology, The First Affiliated Hospital of Soochow

University, 899 Pinghai Road, Suzhou 215008, Jiangsu, China as a potent calcium chelator, antioxidant, and vasodilator for the treatment of calciphylaxis, but there is no significant clinical benefit [3-5]. In addition, the optimal duration, dose, and frequency of off-label administration of STS for patients receiving peritoneal dialysis are unclear. Prospective studies are urgently needed to define the optimal treatment approach. We report here a case of a 40-year-old Chinese male ESRD patient on peritoneal dialysis, who was successfully treated by low-dose and split-course intravenous STS for calciphylaxis with skin lesions.

\section{Case Presentation}

A 40-year-old Chinese man with a 7-year history of peritoneal dialysis of unknown etiology presented with painful necrosis of the fingers and toes for two months. He has a history of hypertension but no diabetes. Before admission, despite changing supportive dressings and 
taking 2 tablets of Celebrex per day, his skin ulcers continued to worsen and the pain could not be relieved. He was finally transferred to our hospital for further evaluation and treatment. He was diagnosed with secondary hyperparathyroidism 2 years before and treated with cinacalcet and lanthanum carbonate, but the effect was not good. Therefore, he underwent total parathyroidectomy and partial forearm implantation half a year prior. After the operation, he developed hypocalcemia and occasional convulsions, which were relieved by changing the peritoneal dialysis protocol and taking oral calcium gluconate. The patient's medications included metoprolo, lanthanum carbonate, compound $\alpha$-ketoacid tablets, folic acid, and ferrous succinate tablets. The patient had no history of warfarin use.

On admission, his height was $173 \mathrm{~cm}$, weight was $67 \mathrm{~kg}$, and body mass index was $22.3 \mathrm{~kg} / \mathrm{m}^{2}$. Physical examination showed necrotic ulcers of varying degrees at the tips of the fingers of both hands and toes of the left foot, covered with thick black scabs (Fig. 1). Laboratory investigations revealed the following results: white blood cell count $6200 / \mu \mathrm{L}$, serum hemoglobin $8.8 \mathrm{~g} / \mathrm{dL}$, platelet count $184000 / \mu \mathrm{L}$, serum calcium $1.52 \mathrm{mmol} / \mathrm{l}$, phosphorus $1.76 \mathrm{mmol} / \mathrm{l}$, serum albumin $2.4 \mathrm{~g} / \mathrm{dL}$, and serum parathyroid hormone $141 \mathrm{pg} / \mathrm{mL}$. The patient was anuric and his $\mathrm{Kt} / \mathrm{V}$ urea was 1.20. The peritoneal equilibration test indicated high average transport. Plain radiographs showed extensive calcification in the upper and lower limbs, including vascular calcifications, small-vessel calcifications, and a net-like pattern of calcifications (Figs. 2 and 3). Skin biopsy during debridement from the relatively normal tissue around the ulcers in his second toe of the left foot revealed focal skin necrosis and polarization of the small artery thrombus but the absence of calcifications. We excluded other possible skin lesions based on the detailed medical history of risk factors, clinical examination, and imaging results. Calciphylaxis was considered given the various related risk factors present in our patient and the quite telling clinical presentation.

We stopped calcium supplementation and performed STS supplement therapy. The patient was treated with intravenous sodium thiosulfate at a low dose (3.2$6.4 \mathrm{~g} / \mathrm{d}$ ) and 5 courses, and there was a nearly 1 -month intermittent period between each course. The specific prescription of the patient is shown in Table 1. The patient was managed meticulously with wound care with frequent dressing changes and periodic debridement by a burn centre and dermatology professional. According to the patient's Kt/V urea, we adjusted the peritoneal dialysis protocol. The calcium and phosphorus metabolism was corrected by using a dialysate with a $1.75 \mathrm{mmol} / \mathrm{l}$ calcium concentration and oral lanthanum carbonate. Analgesic treatment included oral Celebrex (celecoxib capsules) twice a day, and the patient no longer needed analgesics by the fifth course. The patient reported nausea and vomiting only in the third course of treatment, which improved after medication suspension. Therefore, we adjusted the dosage of STS to $3.2 \mathrm{~g} / \mathrm{d}$ in the fourth and fifth courses. After 6 months (5 courses of comprehensive treatment), the patient's skin wound had healed, and the pain was significantly relieved (Fig. 4). During therapy with STS, the clinical and biochemical parameters showed a significant decrease in white blood cells and increased hemoglobin and albumin (Table 2). In addition, no significant reversal of vascular calcification was observed on hand and foot plain films during treatment (Fig. 3). At 9 months after the end of treatment, the patient had no new skin ulcer.

\section{Discussion and conclusions}

Calciphylaxis is a fatal systemic disease that can lead to chronic, painful, non-healing wounds and mainly occurs in patients on maintenance dialysis. Typical histopathological features are systemic arteriolar membranous calcifications, intimal fibrosis, and thrombosis[1]. Fewer reports describe calciphylaxis in peritoneal dialysis patients compared to hemodialysis patients[6]. However, some observational studies have shown that the incidence of this disease is higher in peritoneal dialysis patients than in hemodialysis patients, and the exact mechanism has not been elucidated $[7,8]$. The risk factors for calciphylaxis include female sex, obesity, the number of years on dialysis, hypercalcemia, hyperphosphatemia, secondary hyperparathyroidism, drug use (such as warfarin, calcium, and iron), hypercoagulable state, vitamin $\mathrm{K}$ deficiency, autoimmune diseases, etc. $[1,2]$. We considered the patient's long-term dialysis age, constantly abnormal calcium and phosphorus metabolism, and hyperthyroidism history as possible causes. A study based on Chinese hemodialysis patients showed that high levels of serum phosphate and alkaline phosphatase(ALP) and low levels of serum albumin at the time of diagnosis are independent risk factors for calciphylaxis [9]. Moreover, unlike previous studies in Western countries, men showed an increased risk for calciphylaxis development in this research. The patient we described also has these characteristics, which are be closely related to many factors, such as race.

Calciphylaxis can be classified as central (involving central areas within subcutaneous fatty tissue such as the abdomen or thighs) or peripheral (restricted to peripheral sites with limited fatty tissue on the digits). Central lesions are thought to be more common in dialysis patients. Our patients' lesions occurred in the extremities, and this heterogeneity of skin lesions also attracted our attention, but there is still a lack of relevant research. 


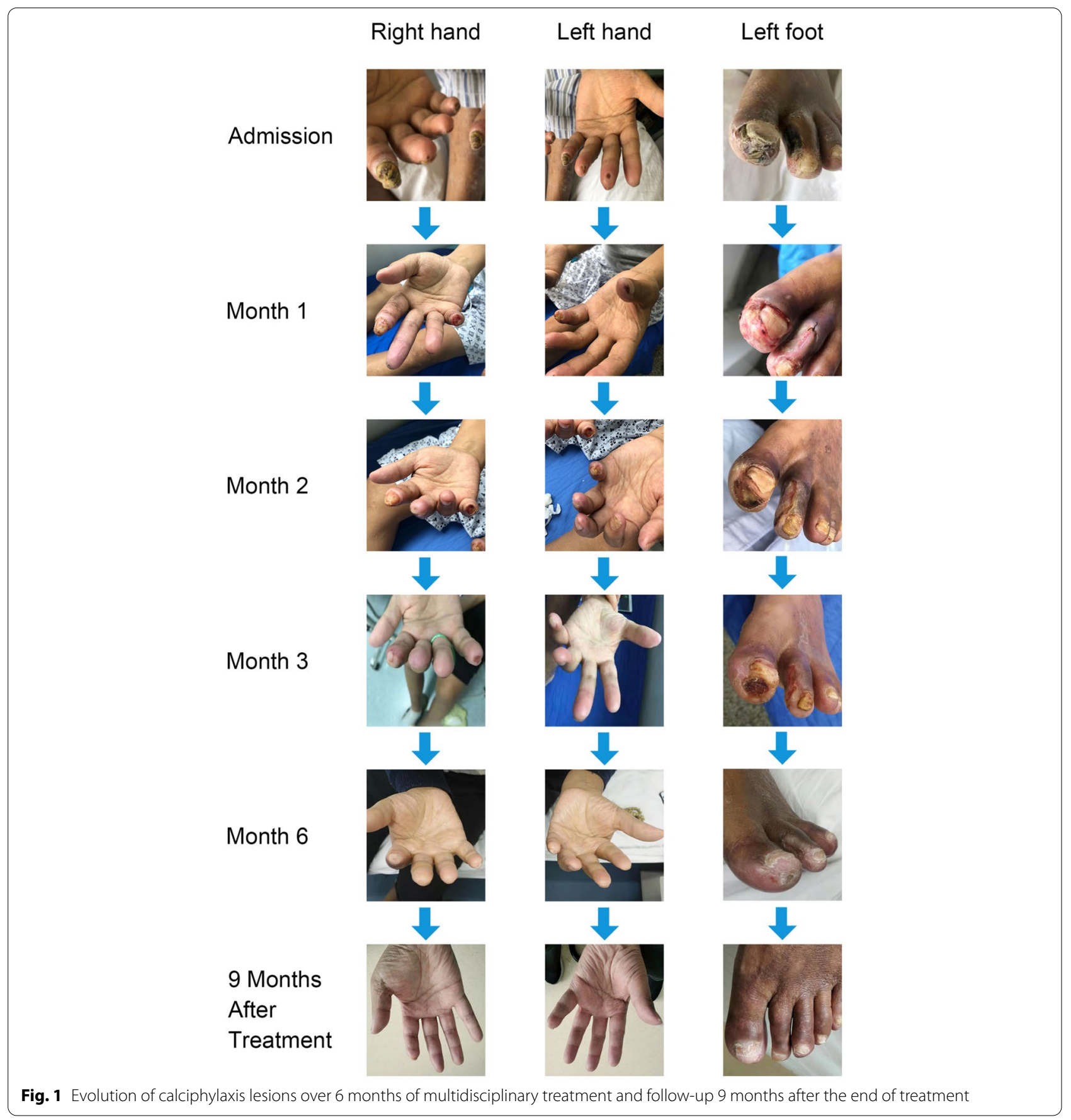

There is no consensus or guidelines on the diagnostic criteria of calciphylaxis to date. A clinical diagnosis can be made for patients with high-risk factors and classic painful necrotic ulcers after excluding other diseases that cause similar skin lesion-like changes $[1,10]$. Our patient presented with typical painful skin lesions on the extremities, visible vascular calcification on imaging, and obvious risk factors. After excluding atherosclerosis, diabetic ulcer, coagulation disorders, and other diseases, calciphylaxis was diagnosed.

Skin biopsy is the standard method for the confirmation of clinically suspected calciphylaxis. However, uniform histologic criteria for diagnosis have not been well established. Moreover, the histologic features of calciphylaxis can be found in unafflicted patients and therefore are not entirely specific [11]. Biopsy also has the risk of 


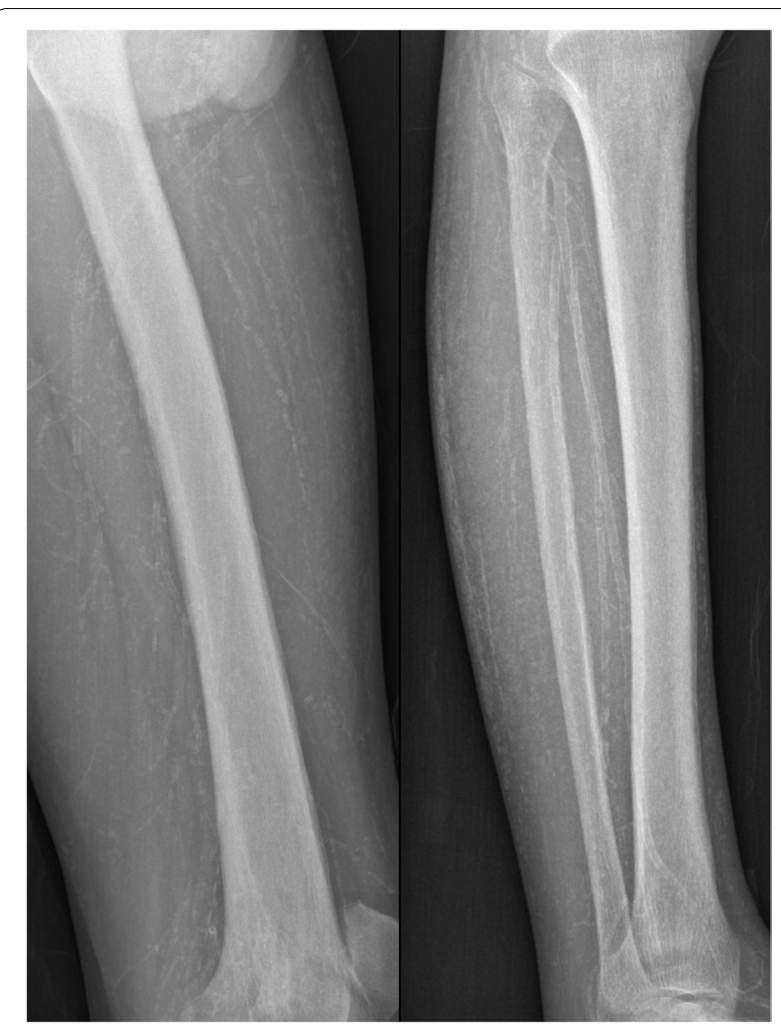

Fig. 2 Plain radiographs of the left thigh and calf show that small-vessel calcification and a net-like pattern of calcification can be observed beyond the locus of ulcer formation

infection, delayed healing, spreading, or the formation of new ulcers [12]. We did not find histological features of typical small vessel calcification in our patient's skin biopsies. Similar cases have been reported in the literature: calcification and other characteristic lesions may be missed because of the histological features of CUA that are punctuated in the subcutaneous tissue [13]. The pathological diagnosis of calciphylaxis usually needs multiple biopsies. Given the risk of infection and the urgent need for timely treatment in our patient, we performed only one skin biopsy during debridement. Recent studies have also confirmed that skin biopsy has a high false-negative rate, which may be related to interpretation and/or sampling issues $[11,14]$. The related factors mentioned above are likely to cause a negative biopsy result in our patient. With its role in practice being debated, many scholars believe that the diagnosis of calciphylaxis requires a comprehensive evaluation of the disease in conjunction with a discussion among multidisciplinary experts and clinicopathology. Skin biopsy should be performed for suspected atypical cases (such as early nonulcerative lesions or no chronic kidney disease) $[1,13]$.

Non-invasive imaging is receiving increasing interest in the diagnosis of calcification. The results of a multi-centre retrospective study supported that the presence of vascular calcification on plain radiography was high sensitivity. A net-like pattern of calcification is a notable feature that may aid in diagnosis [15]. Furthermore, Charles et al. [16]reported that imaging modalities could reveal subcutaneous small vessel calcification in patients with calciphylaxis before histopathological diagnosis. Our case supports these findings and indicates that radiographic imaging can play an essential role for cases of calciphylaxis in which skin biopsy demonstrates thrombotic occlusion and ischemic necrosis but fails to reveal medial arteriolar calcification. Moreover, the plain film of our patient shows that vascular calcification extends beyond the visible skin lesions, which confirms that calciphylaxis is a systemic disease with vessel calcification.

It is currently believed that calciphylaxis treatment requires a multimodal and multidisciplinary approach, including risk factor management, pain management, wound care, medical therapy, and hyperbaric oxygen therapy. Sepsis caused by wound infection is the leading cause of death in patients with calciphylaxis, so wound care is critical. We optimized the dialysis regimen according to the patient's calcium and phosphorus levels to maintain an appropriate balance between calcium and phosphate. We also stopped oral calcium on time to reduce the risks of progression and worsening of calciphylaxis. Given the multiple severe skin ulcers on our patient's extremities, we provided aggressive local wound care, including removing necrotic tissue, frequent dressing changes, and topical ointment to promote healing, in cooperation with dermatologists and professional wound care staff. Pain may be associated with ischemia and neuropathic pain, which is often challenging to treat. Nonsteroidal drugs are the primary drugs used for analgesia management. The patient's pain was significantly relieved in the second and third courses of comprehensive treatment, whose dependence on analgesics was also reduced. The apparent relief of pain improved patient compliance and quality of life and positively impacted the long-term prognosis, as confirmed at the 9-month follow-up.

Although there is no current Food and Drug Administration-approved therapy, sodium thiosulfate, primarily used to treat cyanide poisoning, is increasingly being used off-label to treat calciphylaxis. The therapeutic mechanism of STS action has not yet been fully elucidated. It has been shown to chelate calcium and be removed by dialysis while also having antioxidant and vasodilation properties [3, 17]. STS's common adverse effects include hypocalcemia, hypernatremia, Q-T prolongation, metabolic acidosis, headaches, bone density reduction, nausea, and vomiting [18]. The therapeutic dosage is recommended to dissolve $25 \mathrm{~g}$ of STS in $100 \mathrm{ml}$ of normal saline given intravenously three times a week 

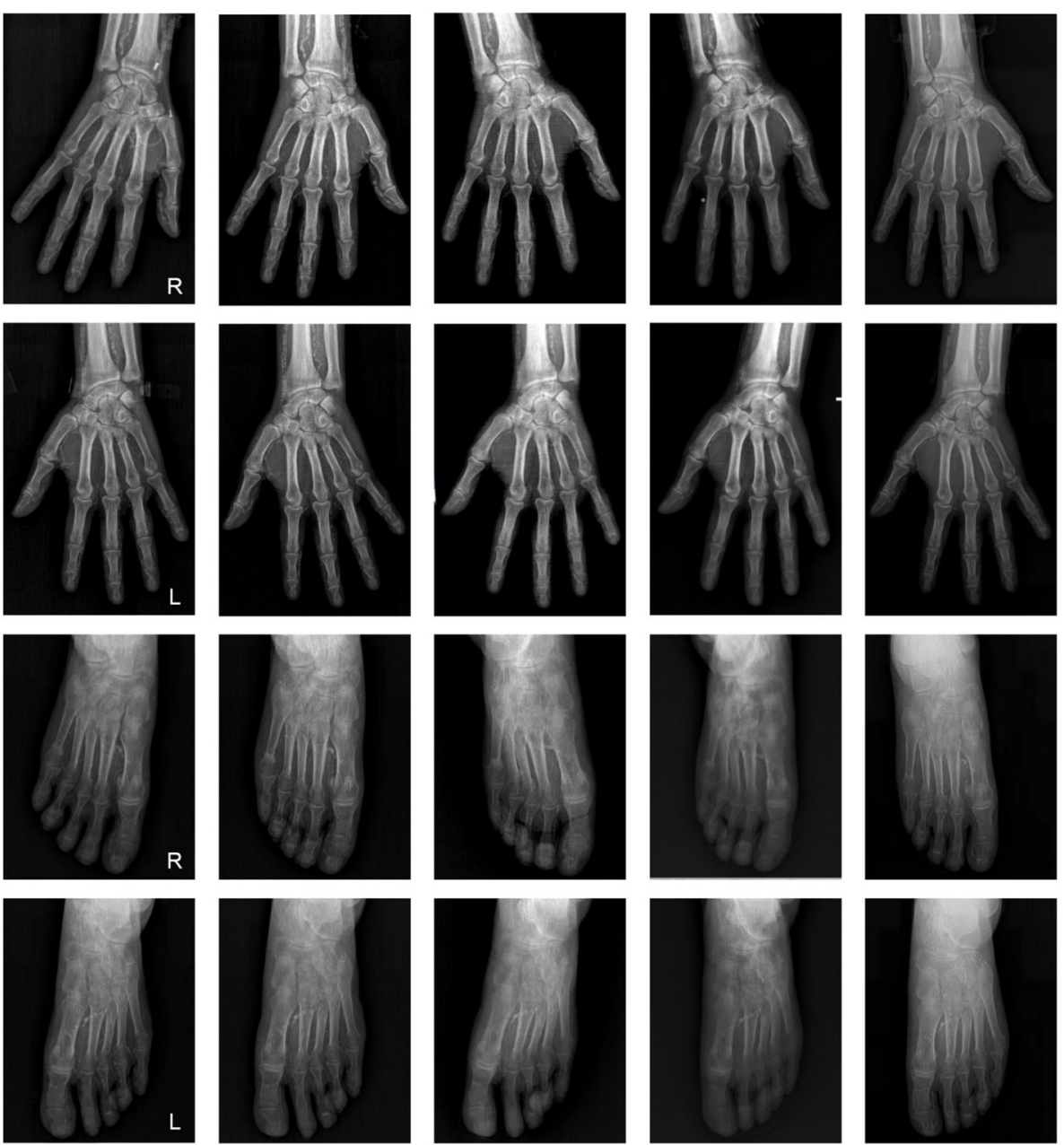

Admission

Month 1

Month 3

Month 6

9 Months

After

Treatment

Fig. 3 Plain radiographs of the hands and feet show severe vascular calcification and no significant reversal after treatment

Table 1 Prescription

\begin{tabular}{|c|c|c|c|c|}
\hline Course & $\begin{array}{l}\text { Duration of } \\
\text { intravenous STS } \\
\text { therapy (days) }\end{array}$ & $\begin{array}{l}\text { Dose } \\
\text { (g/d) }\end{array}$ & Usage & \\
\hline 1 & 28 & $3.2-6.4$ & STS $(3.2 \mathrm{~g})$ is diluted in $50 \mathrm{ml}$ of normal saline and maintained via a venous pump for two hours & Qd \\
\hline 2 & 14 & 6.4 & & Bid \\
\hline 3 & 11 & 6.4 & & Bid \\
\hline 4 & 14 & 3.2 & & Qd \\
\hline 5 & 7 & 3.2 & & Qd \\
\hline
\end{tabular}

during the last 30 to $60 \mathrm{~min}$ of hemodialysis [19]. However, the dosing for patients receiving peritoneal dialysis is unclear. Some scholars have found that the use of classic STS doses in the Chinese population significantly increases the incidence of adverse reactions (such as nausea and vomiting), and patients usually cannot tolerate it [20]. Therefore, we decided to start treatment with multi-course, intravenous, low dose (3.2-6.4 g) sodium 


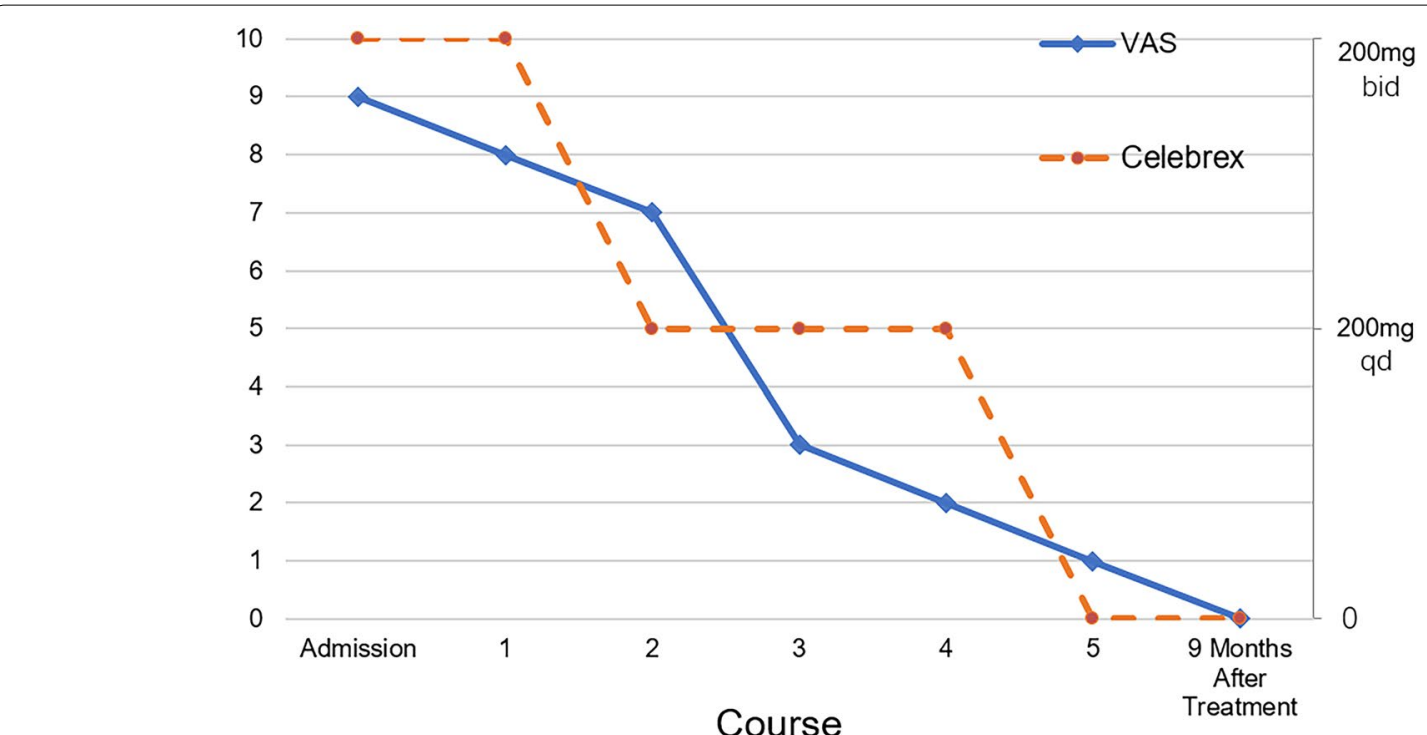

Fig. 4 The VAS score records changes in the degree of pain during treatment and after treatment; the dose change of Celebrex as an analgesic during treatment is also reflected in the figure above

Table 2 Main biochemical and clinical parameters during sodium thiosulfate therapy

\begin{tabular}{|c|c|c|c|c|c|c|c|c|c|}
\hline \multirow[t]{2}{*}{ Parameter } & \multirow[t]{2}{*}{ Before PTX } & \multirow[t]{2}{*}{ Baseline } & \multicolumn{5}{|c|}{ Course } & \multirow{2}{*}{$\begin{array}{l}9 \text { months after } \\
\text { treatment }\end{array}$} & \multirow[t]{2}{*}{ Reference } \\
\hline & & & 1 & 2 & 3 & 4 & 5 & & \\
\hline WBC,10^9/L & 7.18 & 6.2 & 6.03 & 5.14 & 5.56 & 5.64 & 5.44 & 4.7 & $3.5-9.5$ \\
\hline $\mathrm{RBC}, 10 \wedge 12 / \mathrm{L}$ & 2.41 & 3.50 & 3.84 & 4.23 & 4.46 & 4.44 & 4.51 & 4.75 & $4.3-5.8$ \\
\hline $\mathrm{Hb}, \mathrm{g} / \mathrm{L}$ & 66 & 88 & 107 & 110 & 111 & 107 & 111 & 120 & 130-175 \\
\hline $\mathrm{PLT}, 10 \wedge 9 / \mathrm{L}$ & 316 & 184 & 181 & 220 & 172 & 163 & 163 & 149 & $125-350$ \\
\hline NEUT\%,T\% & 0.73 & 0.730 & 0.656 & 0.428 & 0.539 & 0.581 & 0.594 & 0.667 & $0.4-0.75$ \\
\hline Alb, g/L & 34.6 & 24.7 & 30.0 & 30.2 & 31.1 & 29.4 & 27.9 & 31.6 & $40-55$ \\
\hline $\mathrm{ALP}, \mathrm{U} / \mathrm{L}$ & 453.6 & 252.2 & 379.5 & 371.1 & 328.3 & 276.8 & 232.5 & 149 & $45-125$ \\
\hline $\mathrm{Ca}, \mathrm{mmo} / \mathrm{L}$ & 2.18 & 1.52 & 1.87 & 1.81 & 1.60 & 1.33 & 1.53 & 1.72 & $2.11-2.52$ \\
\hline $\mathrm{P}, \mathrm{mmol} / \mathrm{L}$ & 2.77 & 1.76 & 1.53 & 1.45 & 1.59 & 1.79 & 1.75 & 2.33 & $0.85-1.51$ \\
\hline PTH, pg/ml & 200 & 141.1 & - & 198.9 & 212.5 & 201.9 & 253.1 & 131 & $12-88$ \\
\hline
\end{tabular}

PTX Parathyroidectomy

thiosulfate in our patient,according to Yuqiu Liu et al. [21]. This therapy was observed to be effective and tolerated in our peritoneal dialysis patient with CUA. The improvement of the patient's condition also confirmed the diagnosis despite equivocal biopsy results. STS is still an off-label drug used to treat calciphylaxis and requires the approval of relevant agencies and close monitoring of adverse reactions during use. Multi-centre randomized controlled trials are urgently needed to investigate its efficacy, safety, and survival benefit to develop optimal dosing regimens.

For peritoneal dialysis patients, a transition to hemodialysis has been recommended in some studies because hemodialysis may accelerate wound healing by better controlling mineral metabolism [22]. We did not perform this conversion because of our patients' poor vascular condition and the current treatment's effectiveness. We should monitor the patient's dialysis adequacy, and hemodialysis should be considered when necessary.

In conclusion, CUA is a rare disorder with a poor prognosis, and there is currently no guidance or consensus on its treatment. In the current case, we describe a patient on peritoneal dialysis with calciphylaxis. A comprehensive approach with off-label intravenous STS treatment at small dose and divided course resulted in the successful healing of skin lesions after 6 months and showed good 
safety. The research in this field is still insufficient, and medical workers need to create a standardized management protocol.

\author{
Abbreviations \\ CUA: Calcific uremic arteriolopathy; STS: Sodium thiosulfate; ALP: Alkaline \\ phosphatase.
}

\section{Acknowledgements}

We thank Dr. Min Li for her assistance with skin biopsy.

\section{Authors' contributions}

$Y L$ was responsible for designing and performing the data analysis and was a major contributor in writing the manuscript. SL participated in the treatment as primary physician and was responsible for the entire work by properly investigating and resolving issues related to the accuracy or integrity of any part of the work. LZ contributed to the collection and analysis of patient data. DX prepared and described the radiologic data. All authors have read and approved the manuscript.

\section{Funding}

This work was funded by a study on the establishment of a chronic kidney disease management system (No.SS2019055). The funding body played no role in the design of the study and collection, analysis, and interpretation of data or in writing the manuscript.

\section{Availability of data and materials}

All data generated or analysed for this case report are included in this published article.

\section{Declarations}

\section{Ethics approval and consent to participate}

Not applicable

\section{Consent for publication}

Written informed consent was obtained from the patient for publication of this case report and any accompanying images. A copy of the written consent form is available for review by the editor of this journal.

\section{Competing interests}

The authors declare that they have no competing interests.

Received: 10 June 2021 Accepted: 21 December 2021

Published online: 03 January 2022

\section{References}

1. Nigwekar SU, Thadhani R, Brandenburg VM. Calciphylaxis. N Engl J Med. 2018;378(18):1704-14

2. McCarthy JT, El-Azhary RA, Patzelt MT, Weaver AL, Albright RC, Bridges AD, Claus PL, Davis MD, Dillon JJ, El-Zoghby ZM, et al. Survival, Risk Factors, and Effect of Treatment in 101 Patients With Calciphylaxis. Mayo Clin Proc. 2016;91(10):1384-94.

3. Sowers KM, Hayden MR. Calcific uremic arteriolopathy: pathophysiology, reactive oxygen species and therapeutic approaches. Oxid Med Cell Longev. 2010;3(2):109-21.

4. Peng $T$, Zhuo L, Wang $Y$, Jun M, Li G, Wang L, Hong D. Systematic review of sodium thiosulfate in treating calciphylaxis in chronic kidney disease patients. Nephrology (Carlton). 2018;23(7):669-75.

5. Udomkarnjananun S, Kongnatthasate K, Praditpornsilpa K, Eiam-Ong S, Jaber BL, Susantitaphong P. Treatment of Calciphylaxis in CKD: A Systematic Review and Meta-analysis. Kidney Int Rep. 2019;4(2):231-44.

6. Abbas H, Alotaibi M, Lebron RJ. A case report: calciphylaxis presenting as digital ischemia in patient with end stage kidney disease on peritoneal dialysis. Open Journal of Nephrology. 2019;09(02):49-53.
7. Zhang Y, Corapi KM, Luongo M, Thadhani R, Nigwekar SU. Calciphylaxis in peritoneal dialysis patients: a single center cohort study. Int J Nephrol Renovasc Dis. 2016:9:235-41.

8. New N, Mohandas J, John GT, Ratanjee S, Healy H, Francis L, Ranganathan D, Taskapan H. Calcific uremic arteriolopathy in peritoneal dialysis populations. Int J Nephrol. 2011;2011:982854.

9. Liu Y, Zhang X, Xie X, Yang X, Liu H, Tang R, Liu B. Risk factors for calciphylaxis in Chinese hemodialysis patients: a matched case-control study. Ren Fail. 2021:43(1):406-16

10. Seethapathy $H$, Noureddine L. Calciphylaxis: Approach to Diagnosis and Management. Adv Chronic Kidney Dis. 2019;26(6):484-90.

11. Ellis CL, O'Neill WC. Questionable specificity of histologic findings in calcific uremic arteriolopathy. Kidney Int. 2018;94(2):390-5.

12. $M B$ BV, Pieter E, Jürgen F, David G, Rafael K, Ziad M, Sandro M, J SL, Smeeta $\mathrm{S}$, Vicens T, et al. Lack of evidence does not justify neglect: how can we address unmet medical needs in calciphylaxis? Nephrol Dial Transplant. 2016;31(8):1211-9.

13. Rotondi S, De Martini N, Tartaglione L, Muci ML, Petrozza V, Porta N, Leopizzi M, Proietti I, Potenza C, Skroza N, et al. On the role of skin biopsy in the diagnosis of calcific uremic arteriolopathy: a case-based discussion. J Nephrol. 2020;33(4):859-65.

14. Williams EA, Moy AP, Cipriani NA, Nigwekar SU, Nazarian RM. Factors associated with false-negative pathologic diagnosis of calciphylaxis. J Cutan Pathol. 2019:46(1):16-25.

15. Shmidt E, Murthy NS, Knudsen JM, Weenig RH, Jacobs MA, Starnes AM, Davis MD. Net-like pattern of calcification on plain soft-tissue radiographs in patients with calciphylaxis. J Am Acad Dermatol. 2012;67(6):1296-301.

16. Halasz CL, Munger DP, Frimmer H, Dicorato M, Wainwright S. Calciphylaxis: comparison of radiologic imaging and histopathology. J Am Acad Dermatol. 2017;77(2):241-246 e243.

17. Hayden MR, Tyagi SC, Kolb L, Sowers JR, Khanna R. Vascular ossificationcalcification in metabolic syndrome, type 2 diabetes mellitus, chronic kidney disease, and calciphylaxis-calcific uremic arteriolopathy: the emerging role of sodium thiosulfate. Cardiovasc Diabetol. 2005;4:4.

18. Raymond CB, Wazny LD. Sodium thiosulfate, bisphosphonates, and cinacalcet for treatment of calciphylaxis (vol 65, pg 1419, 2008). Am J Health-Syst Ph. 2010;67(1):8-8.

19. Farese S, Stauffer E, Kalicki R, Hildebrandt T, Frey BM, Frey FJ, Uehlinger DE, Pasch A. Sodium thiosulfate pharmacokinetics in hemodialysis patients and healthy volunteers. Clin J Am Soc Nephrol. 2011:6(6):1447-55.

20. Canlin Y, Yuqiu L, Xiaoliang Z. Treatment of calciphylaxis in dialysis patient. Chinese Journal of Nephrology, Dialysis \& Transplantation. 2019;28(06):580-5.

21. Di J, Liu Y, Wang D, Yang M. A Case of Early Calciphylaxis Diagnosed by Bone Scan. Case Rep Med. 2020;2020:9526836.

22. Sprague SM. Painful skin ulcers in a hemodialysis patient. Clin J Am Soc Nephrol. 2014;9(1):166-73.

\section{Publisher's Note}

Springer Nature remains neutral with regard to jurisdictional claims in published maps and institutional affiliations.

Ready to submit your research? Choose BMC and benefit from:

- fast, convenient online submission

- thorough peer review by experienced researchers in your field

- rapid publication on acceptance

- support for research data, including large and complex data types

- gold Open Access which fosters wider collaboration and increased citations

- maximum visibility for your research: over 100M website views per year

At BMC, research is always in progress.

Learn more biomedcentral.com/submissions 